OPEN ACCESS

Edited by: András Székács, National Agricultural Research and Innovation Centre, Hungary

Reviewed by:

Anette Boklund,

Technical University of Denmark,

Denmark

Andrew C. Singer

NERC Centre for Ecology \&

Hydrology, United Kingdom

Miklos Mézes,

Szent István University, Hungary

${ }^{*}$ Correspondence:

Jorge Pinto Ferreira

jorgepintoferreira@gmail.com

Specialty section: This article was submitted to Veterinary Epidemiology and Economics,

a section of the journal Frontiers in Veterinary Science

Received: 30 May 2017 Accepted: 27 November 2017 Published: 12 December 2017

Citation:

Pinto Ferreira J (2017) Why Antibiotic Use Data in Animals Needs to Be Collected and How This Can Be Facilitated.

Front. Vet. Sci. 4:213. doi: 10.3389/fvets.2017.00213

\section{Why Antibiotic Use Data in Animals Needs to Be Collected and How This Can Be Facilitated}

\author{
Jorge Pinto Ferreira* \\ Safoso AG, Liebefeld, Bern, Switzerland
}

Antimicrobial resistance (AMR) is currently recognized as one of the most significant threats to public health worldwide. It is a phenomenon that highlights the interconnectivity between human and animal health since any use of antibiotics in humans can eventually lead to resistance in the microbial populations colonizing animals and vice versa. In recent years, our understanding of the relationship between the use of antibiotics and the consequent development of resistance in microbial populations to these (or similar) antibiotics has increased. Having accurate data, ideally in a digital format, on the use of antibiotics are therefore of paramount importance. Current obstacles to having such data include, among others, the lack of consensual and harmonized technical methods and units that represent antimicrobial use (AMU), the insufficient incentives to motivate primary producers to report their use of antibiotics, and the inexistence of user-friendly technologies for the collection of such data, despite the generalized use of Internet and electronic devices. Further development and adoption of the units proposed by the European Surveillance of Veterinary Antimicrobial Consumption will contribute to the long-desired harmonization. Rewarding the animal producers (via tax incentives, for example) that use less antibiotics and the development of an app, to which producers could orally report the used antibiotics are among the solutions that could help to overcome the current challenges. I here also argue that having mandatory electronic veterinary prescriptions and awareness campaings, funded via public-private partnerships, should also be considered as methods that could help for the control of societal problems like AMR.

Keywords: AMR, AMU, incentives, public health, data collection

\section{INTRODUCTION}

The discovery, availability, and use of antibiotics (antimicrobials in a broader sense) have had a major positive impact on the development and progress of human medicine in the past decades (1). Similarly, antibiotics have also significantly decreased the morbidity and mortality of animals, therefore revolutionizing animal production $(2,3)$. However, this "golden age" seems to be coming to an end (4), with an increasing number of reports highlighting alarming levels of antimicrobial resistance (AMR), including resistance to last resort options (5), and very few new classes of antibiotic being commercialized by the pharmaceutical industry (6). Thus, the range of antimicrobials currently available for use, with little risk of resistance affecting treatment, is dwindling. 
Antimicrobial resistance is a natural phenomenon (7). As most antibiotics are derived from natural sources, microorganisms have been exposed to them throughout evolution; the development of resistance is therefore a natural survival strategy (8). However, the alarming levels of resistance, reported worldwide in animals $(9,10)$, humans $(11,12)$, and the environment (13-15), is generally agreed to be a consequence of the massive use of antibiotics in both humans and animals $(5,16)$ and is also strongly affected by environmental regulator factors $(17,18)$. The economic importance of AMR is also substantial $(19,20)$. Therefore, having accurate and easy to analyze data on antibiotic use is of critical importance, as a step to be able to identify the main specific primary drivers for the downstream development of resistance and tackle them.

\section{THE USE OF DIGITAL DATA ON ANTIBIOTICS UTILIZATION}

Having (digital) data on antimicrobial use (AMU) would allow for:

i. Differentiation of antibiotic use by species treated: at the moment, in the vast majority of countries, it is not yet possible to identify in which species a specific antibiotic has been used. Currently, antibiotics targeting multiple animal species are licensed to be sold with the same commercial name (21). This, in turn, limits the usefulness of sales data as it is therefore not possible to know in which species a specific antibiotic that was sold was used (22). Yet having this information is critical to be able to do source attribution, whereby the ultimate goal is to be able to know, which use, and in which species led to the development of resistance. Once this is possible, risk management options can be implemented;

ii. Identification of good and best practices: being able to identify quantitatively which practices (either at the individual producer level or at the national level) lead to a reduced AMU, while ideally keeping the same productivity in animal rearing (23), is critical. These good practices can then be promoted, through policy change based on a solid evidence base (24);

iii. Identification of a temporal association between AMU and AMR; this is particularly useful when use of a specific product/antibiotic is terminated, either on a voluntary basis (eg. farmers or clinicians) or as a result of a legal ban (25); it is in fact crucial to validate the implementation of such legislative measures, that can also target the use of, for example, heavy metals (like silver, copper, and zinc), that due to co-selection and cross-resistance mechanisms, eventually can also lead to resistance to antibiotics (26). Moreover, there is now an intense debate around how long an antibiotic course should ideally be $(10,27)$, and these data would contribute to clarifying this critical aspect.

iv. Evaluation of specific policies that, for example, target the reduction of AMU: an example of such a policy would be the "yellow card policy" first implemented in Denmark.
Within the scope of this policy, farmers are alerted when their use of antibiotics is above a set threshold based on what would be expected (28). Evaluation of these policies would then allow for their implementation to be adjusted accordingly $(9,25)$.

In the past two decades, we have seen the advent and generalized use of computers, cell phones, and a range of other electronic devices, together with the booming of the Internet. This technology provides a route to unprecedent data access. Data related to AMU in livestock production, for example, could be made open access and thus readily available online for all interested stakeholders (such as policy makers, veterinary services, etc.). However, this is, unfortunately, not yet the case.

Considering the usefulness of AMU data, the availability of technology, and the higher educational levels of the younger livestock producers, it seems that at least some of the major requirements for increased availability of digital AMU are available in more economically developed countries. However, at the moment, very few countries actually have automated digital data collection for AMU (29). Therefore, most current analyses on AMU are based on sales data which have significant limitations as described previously, to which it can be added the fact that the sale of an antibiotic does not provide any information about its actual use (i.e. how, when, where, by whom). It is therefore important to analyze the reasons that can potentially explain this gap between what would be expected (having digital AMU data) and the reality (most frequently, the best available data is sales data).

\section{CURRENT OBSTACLES AND LIMITATIONS}

A critical initial question is: has the scientific community reached a mature and consensual decision regarding which data should be collected and how these should be recorded? Unfortunately, the answer is "not yet" (30). The harmonization and standardization of units and methods to record AMU have long been a goal and pursuit of the scientific community $(31,32)$. Yet at the European level, for example, the animal species for which AMU data is currently collected are quite diverse, with some countries collecting information for all species, while others only collecting it just for the major livestock species (such as pigs or cattle). Furthermore, the technical unit used to measure AMU at the European level can be the Animal Daily Dose (ADD), the Defined Daily Dose (DDD), or simply mg, while the indicators can be, among others, mg/Population Correction Unit (PCU), mg/kg, "Treatment frequency," or "Therapy index" (29).

Although it might seem contradictory, despite the above, Europe can arguably be seen as the leading region (33), in working toward the harmonization of methods. The significant progress and milestones achieved by the European Surveillance of Antimicrobial Consumption (ESVAC) project (such as the publication of the list of Defined Daily Dose (DDDvet)) (34) should be highlighted and recognized. Hopefully, these publications can be used as a guideline or template in other regions of the globe. 
Besides the absence of consensual and harmonized units and methods, other factors have also limited the availability of AMU information:

(i) the right incentives to motivate farmers to record on a digital format their AMU data have not yet been found, thus greatly limiting the amount and quality of data that can be accrued from these primary stakeholders;

(ii) at the moment, much of the attention is given to identify those producers that use more antibiotics (35), which might trigger fear for potential penalties and represent another obstacle to have AMU data;

(iii) despite the plethora of available technology, there is still no appropriate technology that allows for the recording of AMU data in an easy and fast way.

\section{WHICH SOLUTIONS COULD THEREFORE BE IMPLEMENTED TO IMPROVE THE CURRENTLY NON-SATISFACTORY REALITY?}

Solutions designed to collect producer AMU information (such as online platforms, apps, etc.) need to be user-friendly and tailored to the different circumstances (species, countries, languages). Additionally, it is important to include a wide range of different professionals [from IT requirement engineers to social scientists $(36,37)]$ right from the start to ensure that the final product meets its purpose, and has the appropriate medical and pharmaceutical framework behind it. An example of a solution could be a mobile app, that would translate verbal data from producers regarding a specific antibiotic treatment performed, into digital data on AMU. This solution would have also to accommodate the specific use of in-feed antibiotics (38-40), namely species, age group and number of animals fed.

The development of these tools needs to be implemented together with capacity building through educational programs and tailor-made training for the producers themselves to overcome any potential initial resistance or concerns they may have regarding the adoption of newtechnology.

A critical starting point should not be underestimated: if the drugs available on farm can only be purchased after an electronic veterinary prescription, this will already provide data about the "initial pool" of the drugs/antibiotics present/available at a farm (41). The next step should be the collection and recording of the information about the actual use, for example: species, age group and number of animals fed, when considering, for example, infeed antibiotic use.

Having these (mandatory) electronic veterinary prescriptions has several prerequisites: the producer and the veterinarian must first establish a solid and trustful professional relationship, ultimately translated into an actual written contract (vs. an emergencies-based veterinary assistance). As part of this contract, veterinarians should be requested to provide (economic) feedback on the collected data, with the goal of maximizing the economic return of the farm - this will represent a major incentive for farmers to contribute to the AMU electronic data collection, giving them also an important sense of actual ownership and access of the data.

Awareness campaigns will also be another part of the solution. These campaigns should highlight the connection between AMU data and human health, by expounding the concept that providing animal AMU data not only has a direct effect and impact on animal health, but also has spillover effects on human (16) and environmental health (13). Financing such campaigns can be challenging. But AMR is a societal problem (42), for which I argue, public-private funding partnerhsips should be developed out of the best interest of both parts; if it is true that the use of antibiotics/antimicrobials is mostly done in the private sector (particulary on animals) the development of resistance in humans, from animal origin, eventually leads to very significant economic expenses by the different public health authorities (43). And in reality, transmission of pathogens carrying AMR determinants can also happen in the human-animal direction $(44,45)$. The work by Höjgård et al. (46) suggests a societal net benefit, in the specific case of the prevention of the introduction of Livestock-associated Methicillin-resistant Staphylococcus aureus (LA-MRSA) into Sweden and subsequent prevention of human infections (46).

Regardless of the solutions (to increase digital AMU data availability) proposed, the likelihood of their successful uptake will certainly be increased if a bottom-up approach is adopted, whereby the livestock producers' opinions are heard and taken into consideration. Listening to all of them is obviously unrealistic, but umbrella organizations can aggregate their views and express them accordingly.

I here argue that some of the solutions that can contribute to merging the existing gap, between what would be expected, and what is the reality, when it comes to the availability of AMU digital data include:

i. further developments of the harmonization strategy that ESVAC is pursuing;

ii. having veterinary electronic prescriptions of the drugs available on a farm;

iii. requiring the existence of a consultancy contract between farmers and their veterinarians, as well as between feed manufacturers and veterinarians;

iv. creating the (financial) incentives that can enhance farmers' motivations to keep digital data on their AMU;

v. awareness campaigns highlighting the relation between AMR in humans and animals and the consequent usefulness of AMU data;

vi. the development of user-friendly technological options.

Data are increasingly seen as the 21 st century gold and, if collected and analyzed in the proper way, they can indeed contribute to our understanding and control of a societal problem such as AMR. 


\section{AUTHOR CONTRIBUTIONS}

Jorge Pinto Ferreira is a Doctor of Veterinary Medicine with five years of clinical experience (food animals); a Masters in Food Safety; a PhD (as Fulbright scholar) in Public Health with a graduate certificate in Public Policy (NCSU \& Duke); and a recent Diplomate of the European College of Veterinary Public Health. Jorge currently works as aconsultant at SAFOSO AG, where he has been dedicating most of his professional career to AMR. He attended the AHEAD 2017 workshop, where he presented some of the capacity building work that SAFOSO did/ is doing in countries like Vietnam and Ukraine. In this perspective paper, he presents his own perspective about the different aspects related with Antimicrobial Usage (AMU), particularly the reasons behind the availability (or lack of it) of harmonized electronic digital data, and some potential solutions to overcome this.

\section{REFERENCES}

1. Collignon P. Clinical impact of antimicrobial resistance in humans. Rev Sci Tech (2012) 31(1):211-20. doi:10.20506/rst.31.1.2111

2. Rushton J, Pinto Ferreira J, Stärk KD. Antimicrobial resistance: the use of antimicrobials in the livestock sector. OECD Food Agric Fish Pap (2014) 68: 1-37. doi:10.1787/5jxvl3dwk3f0-en

3. Pagel SW, Gautier P. Use of antimicrobial agents in livestock. Rev Sci Tech (2012) 31(1):145-88. doi:10.20506/rst.31.1.2106

4. Elhani D. Lémergence de la résistance aux antibiotiques annonce-t-elle le retour des âges sombres? Ann Biol Clin (2011) 69(6):637-46. doi:10.1684/ abc. 2011.0632

5. Kluytmans J. Plasmid-encoded colistin resistance: mcr-one, two, three and counting. Euro Surveill (2017) 22(31):30588. doi:10.2807/1560-7917. ES.2017.22.31.30588

6. Doshi P. Speeding new antibiotics to market: a fake fix? BMJ (2015) 350:h1453. doi:10.1136/bmj.h1453

7. Bhullar K, Waglechner N, Pawlowski A, Koteva K, Banks ED, Johnston MD, et al. Antibiotic resistance is prevalent in an isolated cave microbiome. PLoS One (2012) 7(4):e34953. doi:10.1371/journal.pone.0034953

8. D'Costa VM, King CE, Kalan L, Morar M, Sung WWL, Schwarz C, et al. Antibiotic resistance is ancient. Nature (2011) 477(7365):457-61. doi:10.1038/ nature 10388

9. Butaye P, van Duijkeren E, Prescott JF, Schwarz S. Antimicrobial resistance in bacteria from animals and the environment. Vet Microbiol (2014) 171(3-4):269-72. doi:10.1016/j.vetmic.2014.04.009

10. Van Boeckel TP, Brower C, Gilbert M, Grenfell BT, Levin SA, Robinson TP, et al. Global trends in antimicrobial use in food animals. Proc Natl Acad Sci U $S$ A (2015) 112(18):5649-54. doi:10.1073/pnas.1503141112

11. Liu YY, Wang Y, Walsh TR, Yi LX, Zhang R, Spencer J, et al. Emergence of plasmid-mediated colistin resistance mechanism MCR-1 in animals and human beings in China: a microbiological and molecular biological study. Lancet Infect Dis (2016) 16(2):161-8. doi:10.1016/S1473-3099(15)00424-7

12. O'Neill J. Tackling Drug-Resistant Infections Globally: Final Report and Recommendations the Review on Antimicrobial Resistance. (2016). Available from: https://amr-review.org/sites/default/files/160525_Final paper_with cover.pdf.

13. Toutain P-L, Ferran AA, Bousquet-Melou A, Pelligand L, Lees P. Veterinary medicine needs new green antimicrobial drugs. Front Microbiol (2016) 7:1196. doi:10.3389/fmicb.2016.01196

14. Lübbert C, Baars C, Dayakar A, Lippmann N, Rodloff AC, Kinzig M, et al. Environmental pollution with antimicrobial agents from bulk drug manufacturing industries in Hyderabad, South India, is associated with dissemination

\section{ACKNOWLEDGMENTS}

This paper was given at the workshop on Digital Transformation of Animal Health Data, which was sponsored by the OECD Co-operative Research Programme: Biological Resource Management for Sustainable Agricultural Systems whose financial support made it possible for the author to participate in the workshop.

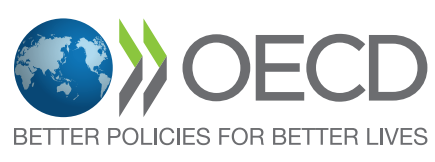

Disclaimer: The opinions expressed and arguments employed in this publication are the sole responsibility of the authors and do not necessarily reflect those of the OECD or of the governments of its Member countries.

of extended-spectrum beta-lactamase and carbapenemase-producing pathogens. Infection (2017) 45(4):479-91. doi:10.1007/s15010-017-1007-2

15. Han Y, Wang J, Zhao Z, Chen J, Lu H, Liu G. Fishmeal application induces antibiotic resistance gene propagation in mariculture sediment. Environ Sci Technol (2017) 51(18):10850-60. doi:10.1021/acs.est.7b02875

16. ECDC (European Centre for Disease Prevention and Control), EFSA (European Food Safety Authority) and European Medicines Agency. ECDC/ EFSA/EMA second joint report on the integrated analysis of the consumption of antimicrobial agents and occurrence of antimicrobial resistance in bacteria from humans and food-producing animals - joint interagency antimicrobial consumption and resistance analysis (JIACRA) report. EFSA J (2017) 15(7):4872,135. doi:10.2903/j.efsa.2017.4872

17. Singer AC, Shaw H, Rhodes V, Hart A. Review of antimicrobial resistance in the environment and its relevance to environmental regulators. Front Microbiol (2016) 7:1728. doi:10.3389/fmicb.2016.01728

18. Ashbolt NJ, Amézquita A, Backhaus T, Borriello P, Brandt KK, Collignon P, et al. Human health risk assessment (HHRA) for environmental development and transfer of antibiotic resistance. Environ Health Perspect (2013) 121(9):993-1001. doi:10.1289/ehp.1206316

19. Smith R, Coast J. The true cost of antimicrobial resistance. BMJ (2013) 346:f1493. doi:10.1136/bmj.f1493

20. Lee BY, Singh A, David MZ, Bartsch SM, Slayton RB, Huang SS, et al. The economic burden of community-associated methicillin-resistant Staphylococcus aureus (CA-MRSA). Clin Microbiol Infect (2013) 19(6):528-36. doi:10.1111/j.1469-0691.2012.03914.X

21. Postma M, Sjölund M, Collineau L, Lösken S, Stärk KDC, Dewulf J, et al. Assigning defined daily doses animal: a European multi-country experience for antimicrobial products authorized for usage in pigs. J Antimicrob Chemother (2015) 70(1):294-302. doi:10.1093/jac/dku347

22. Bondt N, Jensen VF, Puister-Jansen LF, van Geijlswijk IM. Comparing antimicrobial exposure based on sales data. Prev Vet Med (2013) 108(1):10-20. doi:10.1016/j.prevetmed.2012.07.009

23. Collineau L, Rojo-Gimeno C, Léger A, Backhans A, Loesken S, Nielsen EO, et al. Herd-specific interventions to reduce antimicrobial usage in pig production without jeopardising technical and economic performance. Prev Vet Med (2017) 144:167-78. doi:10.1016/j.prevetmed.2017.05.023

24. Speksnijder DC, Mevius DJ, Bruschke CJM, Wagenaar J. Reduction of veterinary antimicrobial use in the Netherlands. The Dutch success model. Zoonoses Public Health (2014) 62:79-87. doi:10.1111/zph.12167

25. Aarestrup FM. The livestock reservoir for antimicrobial resistance: a personal view on changing patterns of risks, effects of interventions and the way forward. Philos Trans R Soc Lond B Biol Sci (2015) 370(1670):20140085. doi:10.1098/rstb.2014.0085 
26. Pal C, Asiani K, Arya S, Rensing C, Stekel DJ, Larsson DGJ, et al. Metal resistance and its association with antibiotic resistance. Adv Microb Physiol (2017) 70:261-313. doi:10.1016/bs.ampbs.2017.02.001

27. Darwin E, Gorton C. The antibiotic course has had its day. BMJ (2017) 358:j3418. doi:10.1136/bmj.j3418

28. Danish Veterinary and Food Administration. Special Provisions for the Reduction of the Consumption of Antibiotics in Pig Holdings (The Yellow Card Initiative).(2013). Available from: https://www.foedevarestyrelsen.dk/english/ SiteCollectionDocuments/Dyrevelfaerd\%20og\%20veterinaermedicin/ Veterin\%C3\%A6rmedicin/Yellow\%20Card,\%20English\%20version,\%20 180517.pdf

29. Ferreira JP, Staerk K. Antimicrobial resistance and antimicrobial use animal monitoring policies in Europe: where are we? J Public Health Policy (2017) 38(2):185-202. doi:10.1057/s41271-017-0067-y

30. Collineau L, Belloc C, Stärk KDC, Hémonic A, Postma M, Dewulf J, et al. Guidance on the selection of appropriate indicators for quantification of antimicrobial usage in humans and animals. Zoonoses Public Health (2017) 64(3):165-84. doi:10.1111/zph.12298

31. Silley P, Simjee S, Schwarz S. Surveillance and monitoring of antimicrobial resistance and antibiotic consumption in humans and animals. Rev Sci Tech (2012) 31(1):105-20. doi:10.20506/rst.31.1.2100

32. Moyaert H, De Jong A, Simjee S, Thomas V. Antimicrobial resistance monitoring projects for zoonotic and indicator bacteria of animal origin: common aspects and differences between EASSA and EFSA. Vet Microbiol (2014) 171(3-4):279-83. doi:10.1016/j.vetmic.2014.02.038

33. European Commission. A European One Health Action Plan against Antimicrobial Resistance (AMR). (2017). Available from: https://ec.europa.eu/ health/amr/sites/amr/files/amr_action_plan_2017_en.pdf.

34. European Medicines Agency. Defined Daily Doses for Animals (DDDvet) and Defined Course Doses for Animals (DCDvet): European Surveillance of Veterinary Antimicrobial Consumption (ESVAC). (2016). 44 p. Available from: http://www.ema.europa.eu/docs/en_GB/document_library/Other/2016/04/ WC500205410.pdf

35. Visschers VHM, Backhans A, Collineau L, Iten D, Loesken S, Postma M, et al. Perceptions of antimicrobial usage, antimicrobial resistance and policy measures to reduce antimicrobial usage in convenient samples of Belgian, French, German, Swedish and Swiss pig farmers. Prev Vet Med (2015) 119(1-2):10-20. doi:10.1016/j.prevetmed.2015.01.018

36. Jensen VF, Jorsal SEL, Toft N. A cross-sectional study of oral antibacterial treatment patterns in relation to specific diarrhoeal pathogens in weaner pigs. Vet Microbiol (2017) 203:18-27. doi:10.1016/j.vetmic.2017.01.038

37. Visschers VHM, Backhans A, Collineau L, Loesken S, Nielsen EO, Postma M, et al. A comparison of pig farmers' and veterinarians' perceptions and intentions to reduce antimicrobial usage in six European countries. Zoonoses Public Health (2016) 63(7):534-44. doi:10.1111/zph.12260

38. Aarestrup FM, Jensen VF, Emborg HD, Jacobsen E, Wegener HC. Changes in the use of antimicrobials and the effects on productivity of swine farms in Denmark. Am J Vet Res (2010) 71(7):726-33. doi:10.2460/ajvr.71.7.726

39. Looft T, Johnson TA, Allen HK, Bayles DO, Alt DP, Stedtfeld RD, et al. In-feed antibiotic effects on the swine intestinal microbiome. Proc Natl Acad Sci U S A (2012) 109(5):1691-6. doi:10.1073/pnas.1120238109

40. Dibner JJ, Richards JD. Antibiotic growth promoters in agriculture: history and mode of action. Poult Sci (2005) 84(4):634-43. doi:10.1093/ps/84.4.634

41. Speksnijder DC, Jaarsma ADC, van der Gugten AC, Verheij TJM, Wagenaar JA. Determinants associated with veterinary antimicrobial prescribing in farm animals in the Netherlands: a qualitative study. Zoonoses Public Health (2015) 62:39-51. doi:10.1111/zph.12168

42. World Health Organization. Global Action Plan on Antimicrobial Resistance. WHOPress(2015).p.1-28.Availablefrom:http://www.who.int/drugresistance/ global_action_plan/en/

43. Marshall BM, Levy SB. Food animals and antimicrobials: impacts on human health. Clin Microbiol Rev (2011) 24(4):718-33. doi:10.1128/CMR.00002-11

44. Ferreira JP, Fowler VG, Correa MT, Lyman R, Ruffin F, Anderson KL. Transmission of methicillin-resistant Staphylococcus aureus between human and hamster. J Clin Microbiol (2011) 49(4):1679-80. doi:10.1128/ JCM.02469-10

45. Morgan M. Methicillin-resistant Staphylococcus aureus and animals: zoonosis or humanosis? J Antimicrob Chemother (2008) 62(6):1181-7. doi:10.1093/jac/ dkn405

46. Höjgård S, Aspevall O, Bengtsson B, Haeggman S, Lindberg M, Mieziewska K, et al. Preventing introduction of livestock associated MRSA in a pig population - benefits, costs, and knowledge gaps from the Swedish perspective. PLoS One (2015) 10(4):e0122875. doi:10.1371/journal.pone.0122875

Conflict of Interest Statement: JF, is a consultant at SAFOSO, a private company, based in Bern, Switzerland, that routinely is engaged in different research projects [including about AntiMicrobial Resistance (AMR)], funded by for example the European Union, and similar funding bodies.

Copyright (C) 2017 Pinto Ferreira. This is an open-access article distributed under the terms of the Creative Commons Attribution License (CC BY). The use, distribution or reproduction in other forums is permitted, provided the original author(s) or licensor are credited and that the original publication in this journal is cited, in accordance with accepted academic practice. No use, distribution or reproduction is permitted which does not comply with these terms. 